\title{
Electrochemical promotion of CO combustion over Pt/YSZ under high vacuum conditions
}

\author{
Chun Xia ${ }^{a, b, c}$, Cyril Falgairette ${ }^{b}$, Yongdan Li ${ }^{c}$, György Foti ${ }^{b}$, Christos Comninellis ${ }^{b}$, Wolfgang Harbich ${ }^{a, *}$ \\ a Institute of Condensed MatterPhysicsEcole Polytechnique Fédérale de Lausanne, CH-1015, Lausanne, Switzerland \\ ${ }^{\mathrm{b}}$ Institute of Chemical Sciences and Engineering EcolePolytechniqueFédérale de Lausanne, CH-1015, Lausanne, Switzerland

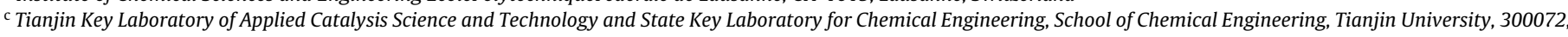 \\ Tianjin, China
}

\section{A R T I C L E I N F O}

\section{Article history:}

Received 12 October 2010

Received in revised form

22 November 2011

Accepted 24 November 2011

Available online $\mathrm{xxx}$

\section{Keywords:}

Electrochemical promotion

$\mathrm{Pt} / \mathrm{YSZ}$

Oxygen storage

High vacuum

Persistent electrochemical promotion

\begin{abstract}
A B S T R A C T
Electrochemical promotion of CO combustion over Pt/YSZ was investigated under high vacuum conditions. A galvanostatic step was coupled to mass spectrometric gas analysis using an electrochemical mass spectrometric monitoring device. Non-Faradaic electrochemical promotion of catalysis took place at $300^{\circ} \mathrm{C}$ while only electrochemical oxidation was observed at $400^{\circ} \mathrm{C}$. Oxygen evolution measurements revealed that electrochemical promotion is related to the thermodynamically stable $\mathrm{PtO}_{x}$ species over the Pt/gas interface. The polarization time and $\mathrm{O}_{2}$ pressure show strong influence on the relaxation transient upon current interruption. We propose that during anodic polarization, $\mathrm{PtO}_{x}$ is first formed at the Pt/YSZ interface. With prolonged polarization time, the formed $\mathrm{PtO}_{x}$ either migrates over the Pt/gas interface inducing electrochemical promotion or diffuses into the Pt bulk leading to the oxygen storage. After polarization, the stored $\mathrm{O}$ species is released and acts as sacrificial promoter causing the persistent electrochemical promotion effect.
\end{abstract}

(C) 2011 Elsevier B.V. All rights reserved.

\section{Introduction}

The catalytic activity of metal and metal oxide catalysts, deposited on solid electrolytes (e.g. $\mathrm{Y}_{2} \mathrm{O}_{3}$-stabilized $\mathrm{ZrO}_{2}$, YSZ), can be increased in a pronounced manner by current or potential application between the catalyst and a gold electrode in an electrochemical cell of the type:

Gaseous reactants, catalyst|solid electrolyte|Au electrode, gaseous reactants

This is reported in the literature as electrochemical promotion (EP) or as non-Faradaic electrochemical modification of catalytic activity (NEMCA). It has been studied during the last few years for several reactions using different catalysts and solid electrolytes [1-3].

The commonly proposed model of EP over Pt/YSZ attributes this phenomenon to electrochemically formed species, i.e. $\mathrm{O}^{\delta-}$, migrating from the solid electrolyte to the surface of catalyst inducing a work function (WF) change on the metal surface. These oxygen promoters weaken the catalyst- $O$ bond of chemisorbed oxygen atoms which leads to an increase in catalytic rate [4]. Numerous analytical probe techniques, e.g. X-ray photoelectron spectroscopy

\footnotetext{
* Corresponding author.

E-mail address: wolfgang.harbich@epfl.ch (W. Harbich).
}

(XPS), photoelectron emission microscopy (PEEM), scanning tunneling microscopy (STM), temperature programmed desorption (TPD) coupled to an electrochemical perturbation have been used to monitor (qualitatively and quantitatively) the oxygen species [5-8]. However, few papers reveal the relation between the detected $\mathrm{O}$ species and EP effect. Due to the complexity of the system, the electrochemical behavior of a metal/YSZ cell in EP is still not fully understood [9].

In order to shed more light on these processes, a high vacuum (HV) setup was built to perform the electrochemical investigation over Pt/YSZ at $400^{\circ} \mathrm{C}$ as described recently [10]. Under anodic polarization, oxygen evolution reactions are identified. We assume that $\mathrm{PtO}_{x}$ is formed at both the $\mathrm{Pt} / \mathrm{YSZ}$ and the Pt/gas interface according to two different mechanisms [11]. The $\mathrm{PtO}_{x}$ species on the Pt/gas interface acts as oxygen promoter and induces the EP effect. At the Pt/YSZ interface, $\mathrm{PtO}_{x}$ formation is an electrochemical process following a parabolic growth law, while the presence of $\mathrm{PtO}_{x}$ at the Pt/gas interface is related to the diffusion of $\mathrm{PtO}_{x}$ formed at the triple phase boundary (TPB) towards the Pt/gas interface [12]. However, the stability of $\mathrm{PtO}_{x}$ is thermodynamically not favored at $400{ }^{\circ} \mathrm{C}$ under $\mathrm{HV}$ conditions restraining the appearance of EP [11]. In order to investigate the influence of $\mathrm{PtO}_{x}$ on EP, decreasing the operation temperature to stabilize $\mathrm{PtO}_{x}$ seems an alternate way according to thermodynamic data [13]. 
In this work, a galvanostatic step is imposed to the Pt/YSZ interface in the presence of reactants $\left(\mathrm{O}_{2}\right.$ and $\left.\mathrm{CO}\right)$ at lower temperature (e.g. $300^{\circ} \mathrm{C}$ ) under $\mathrm{HV}$ conditions and the products are analyzed online by mass spectrometry (MS). Based on the assumption that $\mathrm{PtO}_{x}$ is formed during polarization, the influence of electrochemically formed $\mathrm{PtO}_{x}$ on the EP at various operation conditions (temperature, polarization time and $\mathrm{O}_{2}$ pressure) is discussed. A dynamic model of EP over a Pt/YSZ cell is proposed based on these experimental facts.

\section{Experimental}

A commercial zirconia pellet stabilized by $8 \mathrm{~mol} \% \mathrm{Y}_{2} \mathrm{O}_{3}$ (Technox 802, Dynamic Ceramic Ltd.) was used as substrate on which a platinum electrode was deposited by magnetron sputtering in $\mathrm{Ar}$ at room temperature. The magnetron operates in the direct current (dc) mode maintaining a discharge of $330 \mathrm{~V}$ at an Ar pressure of $1 \mathrm{~Pa}$. Under these conditions, a $1 \mu \mathrm{m}$ thick Pt electrode was deposited with a deposition rate of $0.09 \mathrm{~nm} \mathrm{~s}^{-1}$ on the YSZ pellet as determined by profilometric measurements (Alphastep, Model 500) of the film deposited on smooth silicon samples processed simultaneously. The size of Pt working electrode is $7 \mathrm{~mm} \times 5 \mathrm{~mm}$ giving a geometric surface of $0.35 \mathrm{~cm}^{2}$. The Pt working and Au counter electrodes were located in a symmetrical face-to-face arrangement on the opposite side of the YSZ pellet with the Au reference electrode lying next to the counter electrode. This geometry ensured a symmetrical current and potential distribution in the cell [14]. Before using, the sample has been treated at $700^{\circ} \mathrm{C}$ in $20 \mathrm{kPa} \mathrm{O}_{2}$ during $4 \mathrm{~h}$ in order to stabilize the porous platinum electrode films [15].

Electrochemical measurement were carried out under high vacuum (HV) conditions with a background pressure of $10^{-6} \mathrm{~Pa}$ by solid electrochemical mass spectroscopy (EMS) using a setup described in detail elsewhere [10]. This electrochemical technique involves the imposition of an electrochemical perturbation (Autolab, Metrohm, and PGSTAT30) to the system while monitoring directly by mass spectrometry (QMS, Pfeiffer, Prisma200) the formation of products released into the gas phase. If needed, the reactants i.e. $\mathrm{O}_{2}$ (46 purity Carbagas certified) and $\mathrm{CO}$ (60 purity Carbagas certified), are introduced into the reactor via HV leak valves and capillary stainless steel gas lines. Total pressure is monitored by a cold cathode pressure gage.

In this work, the EMS technique is used under the following conditions:

- Perturbation of the Pt/YSZ interface with an applied current of $10 \mu \mathrm{A}$ at $300^{\circ} \mathrm{C}$ and $400^{\circ} \mathrm{C}$ in the absence of reactive gas.

- Measurements of electrochemical promotion at an applied current of $4 \mu \mathrm{A}$ in the presence of $\mathrm{CO}$ and $\mathrm{O}_{2}$ at $300^{\circ} \mathrm{C}$. In addition, a galvanostatic step was imposed to Pt/YSZ cell for a variety of polarization time and at different $\mathrm{O}_{2}$ pressure.

During the measurements, all gas products are monitored online. The response time of the system is $0.5 \mathrm{~s}$.

\section{Results}

\subsection{Anodic polarization in the absence of reactive gas}

Fig. 1 shows the transient effect on the oxygen evolution over $\mathrm{Pt} / \mathrm{YSZ}$ at $300^{\circ} \mathrm{C}$ and $400^{\circ} \mathrm{C}$ in the absence of reactive gas at a background pressure of $10^{-6} \mathrm{~Pa}$. When a current of $10 \mu \mathrm{A}$ is applied between the Pt working electrode and the counter electrode, oxygen evolution is observed by MS at both temperatures. During the galvanostatic step, zirconia is electrochemically reduced at the cathode to release $\mathrm{O}^{2-}$ which migrates to the anode across YSZ

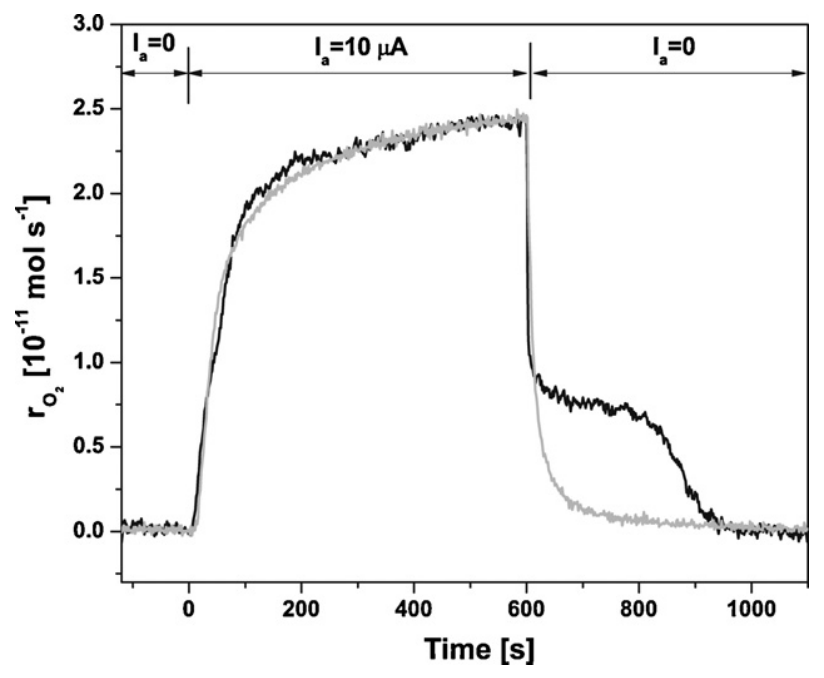

Fig. 1. The transient effect of anodic polarization on the oxygen evolution over $\mathrm{Pt} / \mathrm{YSZ}$ cell at $300^{\circ} \mathrm{C}$ (gray) and $400^{\circ} \mathrm{C}$ (black) at a background pressure of $10^{-6} \mathrm{~Pa}$.

according to reaction (R1) [16]. When the potential of Pt electrode (vs. gold reference) is higher than $300 \mathrm{mV}$ [11], oxygen evolution takes place at the triple phase boundary (TPB) of the anode according to reaction $(\mathrm{R} 2)$ :

$\mathrm{ZrO}_{2}+2 \delta e^{-}=\mathrm{ZrO}_{2-\delta}+\delta \mathrm{O}^{2-}$

$\mathrm{O}^{2-}=1 / 2 \mathrm{O}_{2}+2 e^{-}$

Upon current interruption, the flux of evolved $\mathrm{O}_{2}$ decreases back to zero within $1 \mathrm{~min}$ at $300^{\circ} \mathrm{C}$ while at $400^{\circ} \mathrm{C}$ a plateau is observed before returning to the initial open circuit value. This unexpected plateau also occurred in both MS-cyclic voltammetry (MS-CV) and MS-double step chronopotentiometry (MS-DSCP) measurements at the same conditions [11]. During anodic polarization, a fraction of $\mathrm{PtO}_{x}$ forms at the TPB according to reaction (R3) and diffuses to the Pt/gas interface. However, the thermodynamic instability of $\mathrm{PtO}_{x}$ under high vacuum conditions at $400^{\circ} \mathrm{C}$ results in $\mathrm{O}_{2}$ release (reaction (R4)).

$\mathrm{Pt}+x \mathrm{O}^{2-}=\mathrm{PtO}_{x}+2 x e^{-}$

$\mathrm{PtO}_{x}=x / 2 \mathrm{O}_{2(\mathrm{~g})}+\mathrm{Pt}$

In contrast, the stabilization of $\mathrm{PtO}_{x}$ becomes thermodynamically favored at $300^{\circ} \mathrm{C}$ under the same atmosphere, which limits $\mathrm{PtO}_{x}$ decomposition after polarization which explains the behavior as depicted in Fig. 1.

\subsection{Anodic polarization in the presence of reactive gases}

Fig. 2 presents the transient effect of an applied current of $4 \mu \mathrm{A}$ on the catalytic rate of $\mathrm{CO}$ combustion at $300^{\circ} \mathrm{C}\left(P_{\mathrm{CO}}=1.5 \times 10^{-3} \mathrm{~Pa}\right.$ and $\left.P_{\mathrm{O}_{2}}=4.4 \times 10^{-4} \mathrm{~Pa}\right)$. In EP experiments, two important parameters are commonly used to quantify the magnitude of the phenomenon, the rate enhancement ratio, $\rho$, and the Faradaic efficiency, $\Lambda$, as defined by Eqs. (1) and (2):

$\rho=\frac{r_{\mathrm{CO}_{2}}}{r_{\mathrm{CO}_{2}}^{0}}$

and

$\Lambda=\frac{\left(r_{\mathrm{CO}_{2}}-r_{\mathrm{CO}_{2}}^{0}\right)}{(I / 2 F)}$ 


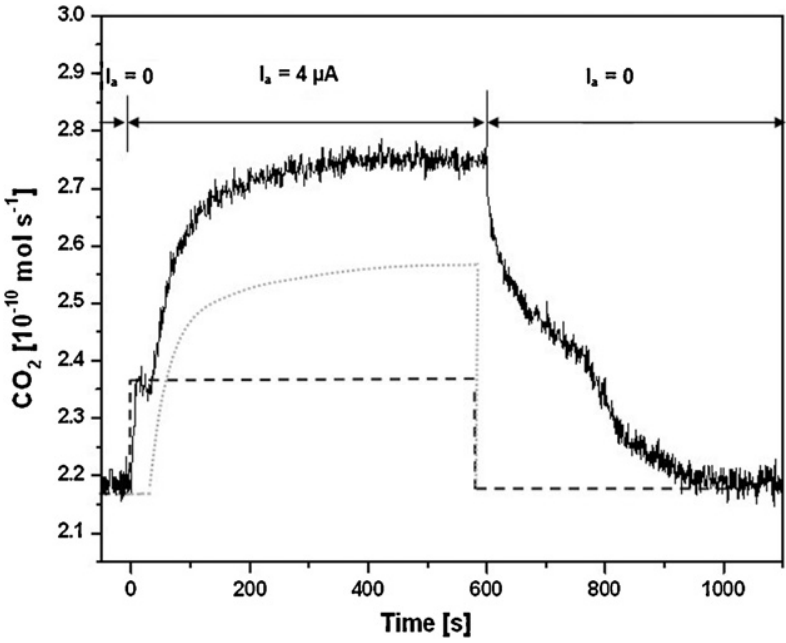

Fig. 2. The transient effect of an applied current of $4 \mu \mathrm{A}$ on the catalytic rate of $\mathrm{CO}$ combustion at $300^{\circ} \mathrm{C}\left(P_{\mathrm{CO}}=1.5 \times 10^{-3} \mathrm{~Pa}, P_{\mathrm{O}_{2}}=4.4 \times 10^{-4} \mathrm{~Pa}\right)$. (-- ) Faradaic rate, (...)non-Faradaic rate.

where $r_{\mathrm{CO}_{2}}$ and $r_{\mathrm{CO}_{2}}^{0}$ are the electropromoted and the initial open circuit rate, respectively, of $\mathrm{CO}$ combustion (R5) expressed in $\mathrm{mol} \mathrm{s}^{-1}$ and $F$ is Faraday's constant.

$\mathrm{CO}+1 / 2 \mathrm{O}_{2}=\mathrm{CO}_{2}$

The open circuit rate yields $r_{\mathrm{CO}_{2}}^{0}=2.2 \times 10^{-10} \mathrm{~mol} \mathrm{~s}{ }^{-1}$. The application of a $4 \mu \mathrm{A}$ current causes a 1.3-fold increasing of the catalytic rate, i.e. $\rho=1.3$. The Faradaic efficiency, $\Lambda$, equals to 2.7 indicating a non-Faradaic process. Worth to note that a small plateau in the $\mathrm{CO}_{2}$ production with a length of $60 \mathrm{~s}$ is observed before the catalytic rate reaches steady state. The value of this $\mathrm{CO}_{2}$ plateau equals the Faradaic rate, $I / 2 \mathrm{~F}$. This is an important observation as it implies that electrochemical oxidation of CO takes place at the TPB before electrochemical promotion occurs. Therefore, the transient reaction under polarization can be easily divided into two processes, i.e. the Faradaic process (reaction (R6)) and the non-Faradaic process (reaction (R5)), as shown in Fig. 2.

$\mathrm{CO}+1 / 2 \mathrm{O}^{2-}=\mathrm{CO}_{2}+2 e^{-}$

Upon current interruption, the catalytic rate decreases and a $400 \mathrm{~s}$ relaxation time is needed to obtain the initial open circuit rate. Such reaction relaxation is reported as persistent-EP (pers-EP) which is related to the oxygen storage during polarization $[17,18]$.

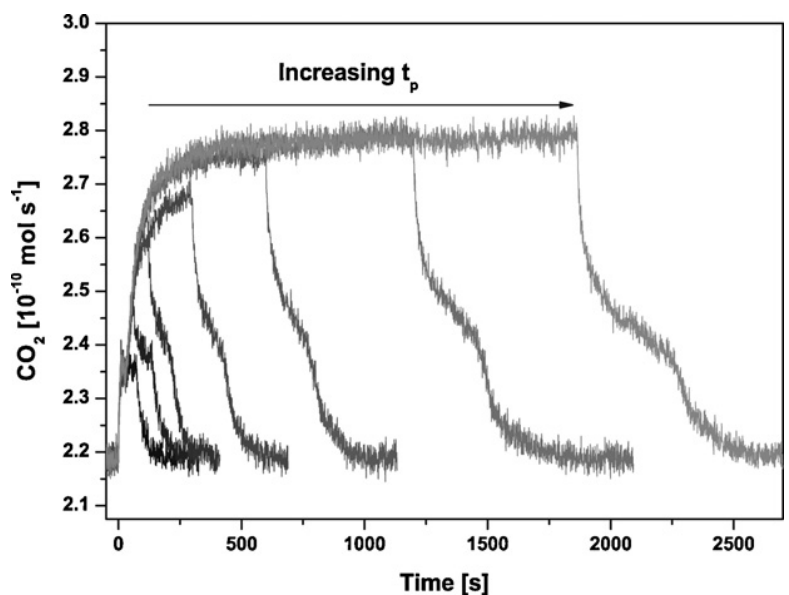

Fig. 3. The influence of holding time, $t_{\mathrm{p}}$, at $4 \mu \mathrm{A}$ on the EP performance. $t_{\mathrm{p}}$ increases from 30 s to 1800 s. Conditions: idem Fig. 2.

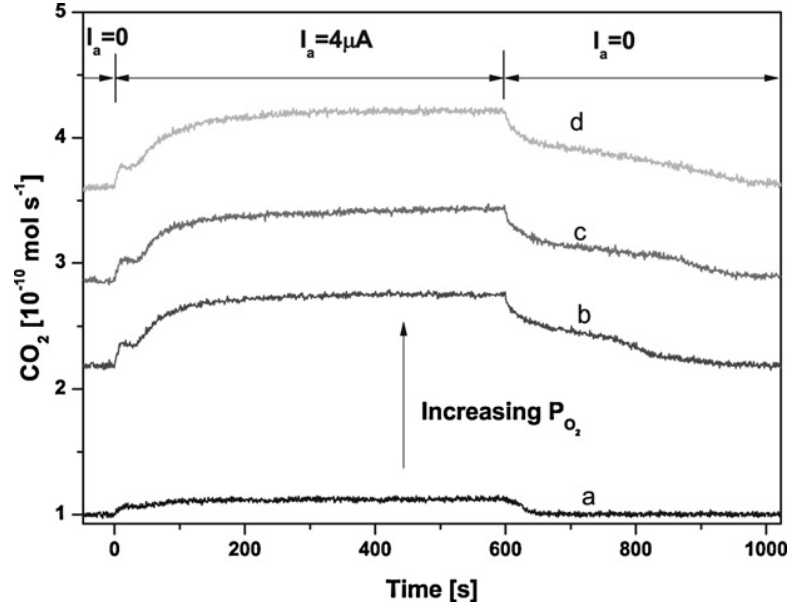

Fig. 4. The influence of $\mathrm{O}_{2}$ pressure on the EP transient effect of $\mathrm{CO}$ oxidation at an applied current of $4 \mu \mathrm{A}$. $\mathrm{O}_{2}$ pressure, $P_{\mathrm{O}_{2}}$ (a) $4.8 \times 10^{-5} \mathrm{~Pa}$, (b) $4.4 \times 10^{-4} \mathrm{~Pa}$, (c) $9 \times 10^{-4} \mathrm{~Pa}$, (d) $1.5 \times 10^{-3} \mathrm{~Pa} . P_{\mathrm{CO}}=1.5 \times 10^{-3} \mathrm{~Pa} . T=300^{\circ} \mathrm{C}$.

Fig. 3 presents the influence of polarization time, $t_{\mathrm{H}}$, on the transient effect of catalytic rate at $300^{\circ} \mathrm{C}$ in the presence of reactive gases. A galvanostatic step of $4 \mu \mathrm{A}$ was applied for various holding times from $30 \mathrm{~s}$ to $1800 \mathrm{~s}$. It is observed that the initial $\mathrm{CO}_{2}$ plateau is independent on the polarization time. In addition, once the steady state catalytic rate is reached at $t=400 \mathrm{~s}$, it remains constant independent on the duration of prolonged anodic polarization. In contrast, longer and longer relaxation times are required to attain the initial open circuit rate upon current interruption by increasing the polarization time. Indeed, the shape of the relaxation transient strongly depends on $t_{\mathrm{p}}$, but it has no effect on the electropromoted steady state rate during polarization. This strongly indicates that the polarization at long $t_{\mathrm{p}}$ must influence a part of the system which is not exposed to the catalytic reaction. At current interruption, this "hidden" influence becomes visible, so the species implicated must reach the active catalytic surface of the system [19].

The reaction rate transients during application of a constant anodic current on the $\mathrm{CO}_{2}$ catalytic rate for varying $\mathrm{O}_{2}$ pressure are presented in Fig. 4. At low $\mathrm{O}_{2}$ pressure $\left(4.8 \times 10^{-5} \mathrm{~Pa}\right)$, the polarization of the Pt/YSZ cell only causes predominantly a Faradaic increase of the catalytic rate $(\Lambda<1)$. Most of the $\mathrm{CO}_{2}$ product forms due to the electrochemical oxidation of $\mathrm{CO}$ at the TPB.

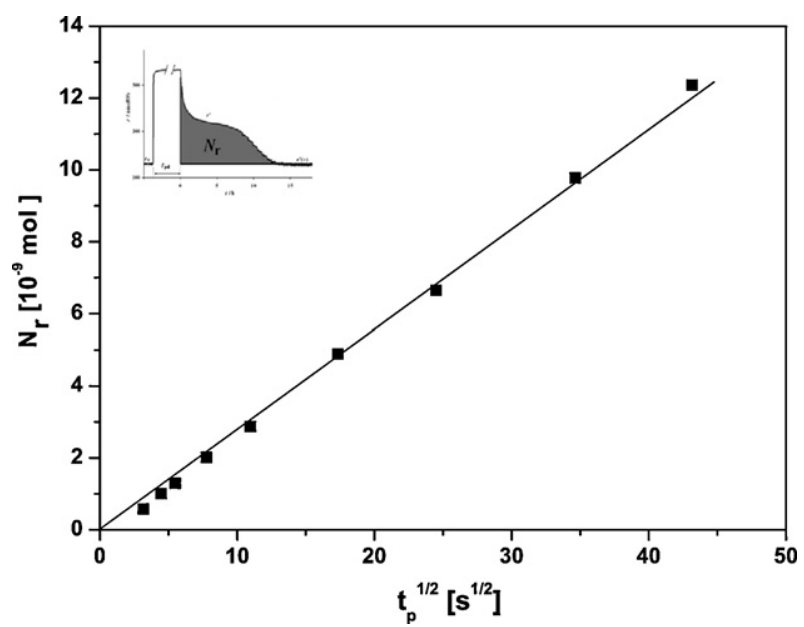

Fig. 5. Integrated amount of oxygen species, $N_{\mathrm{r}}$, consumed via CO combustion after current interruption as a function of the square root of polarization time, $t_{\mathrm{p}}^{1 / 2}$, in Fig. 3. 


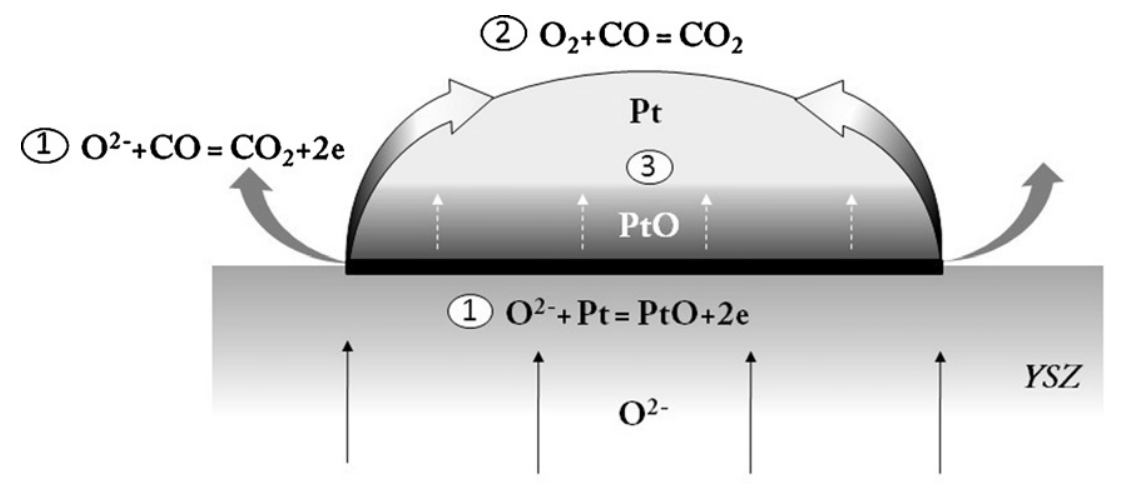

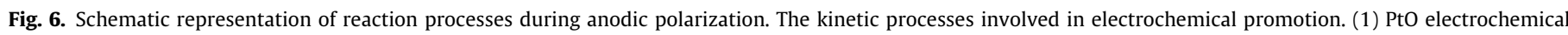

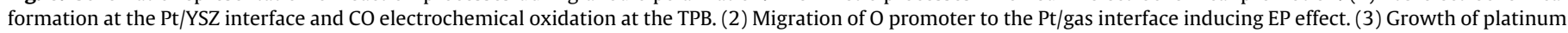
oxide from the Pt/YSZ interface into Pt bulk leading to pers-EP after polarization.

With increasing $\mathrm{O}_{2}$ pressure, the promoted rate strongly increases, evidencing both the $\mathrm{CO}_{2}$ plateau at the beginning of polarization and the independence or saturation of the promoted rate. In contrast, the variation of $\mathrm{O}_{2}$ pressure has an important influence on the pers-EP, i.e. longer relaxation time under higher $\mathrm{O}_{2}$ pressure.

\section{Discussion}

In our previous paper, the electrochemical measurements were carried out over a Pt/YSZ cell at $400{ }^{\circ} \mathrm{C}$ under a background pressure of $10^{-6} \mathrm{~Pa}$. The polarization only caused a Faradaic increase of the catalytic rate with $\Lambda=0.1$ [11]. The lack of non-Faradaic processes is attributed to the thermodynamic instability of $\mathrm{PtO}_{x}$ under operation conditions according to [13]. The unstable $\mathrm{PtO}_{x}$ species either reacts with $\mathrm{CO}$ forming $\mathrm{CO}_{2}$ or to desorb in the form of $\mathrm{O}_{2}$ (Fig. 1). In contrast, when the cell temperature decreases to $300^{\circ} \mathrm{C}$, a non-Faradaic rate is observed as depicted in Fig. 2. Under this condition, the stabilization of surface $\mathrm{PtO}_{x}$ is thermodynamically favored. $\mathrm{PtO}_{x}$ species stabilized on the Pt surface lead to the appearance of EP which is in agreement with HV results reported by Katsaounis et al. [20].

In the literature, either the EP effect on the catalytic rate or the existence of surface $\mathrm{O}$ species under polarization is discussed. Here we give evidence that the EP effect is determined by the electrochemically formed $\mathrm{O}$ species over the Pt/gas interface as in the "sacrificial" promoter mechanism of EP proposed by Vayenas et al. [4].

The phenomenon of pers-EPOC after polarization was first observed in the $\mathrm{C}_{2} \mathrm{H}_{4}$ combustion over Pt/YSZ at high temperature $\left(500-600^{\circ} \mathrm{C}\right)$ under ambient pressure [21]. For a better understanding, a series of techniques such as single and double step chronoamperometry, chronocoulometry and programmed cyclic voltammetry were performed as reported in [22]. They indicated that application of an anodic polarization on the Pt/YSZ system caused short and long term oxygen storage in the working electrode. Upon current interruption, the stored $O$ species are released to the catalytic Pt surface and act as the sacrificial promoters leading to pers-EPOC. In Fig. 3, prolonged polarization presents significant influence on pers-EPOC rather than on electropromoted steady state rate indicating that stored oxygen species are hidden in the non-gas exposed location, i.e. Pt/YSZ interface and Pt bulk [15]. By integration of the relaxation part as shown in Fig. 5, the total amount of consumed $\mathrm{O}$ atoms, $N_{\mathrm{r}}$, is found to be proportional to $t_{\mathrm{H}}^{1 / 2}$. According to the oxygen storage model, upon current interruption, the stored oxygen species is released over the Pt surface and act as sacrificial promoter inducing pers-EPOC. Actually, the relaxation part $N_{\mathrm{r}}$ is composed of two parts, i.e. consumption of stored oxygen promoter $N_{\mathrm{p}}$ and absorbed oxygen from gas phase
$N_{\mathrm{o}}$ as Eq. (3). The amount of the latter is directly determined by former as Eq. (4). Thus, the integration of the transient part is a reasonable way to characterize the change of the stored oxygen promoter as a function of polarization time.

$N_{\mathrm{r}}=N_{\mathrm{p}}+N_{\mathrm{o}}$

$N_{\mathrm{o}}=A \times N_{\mathrm{p}}$

where $A$ is termed as persistent constant.

From Eqs. (3) and (4)

$N_{\mathrm{r}}=N_{\mathrm{p}(1+A)}$

According to Fig. 5 and Eq. (5), the amount of stored oxygen promoter, $N_{\mathrm{p}}$, also obeys the $t_{\mathrm{H}}^{1 / 2}$ kinetic law as $N_{\mathrm{r}}$, typical for diffusion controlled processes [21]. This supports the idea of oxygen diffusion from the Pt/YSZ interface into the Pt bulk under prolonged polarization. The amount of deposited Pt can be considered as an infinite reservoir. Furthermore, the increase of $P_{\mathrm{O}_{2}}$ has a dramatic impact not only on EPOC but also on pers-EPOC. Higher $\mathrm{O}_{2}$ pressure is in favor of pers-EP leading to longer relaxation time as depicted in Fig. 4.

The dynamic model of electrochemical promotion over Pt/YSZ cell is schematically shown in Fig. 6. In reactive atmosphere, $\mathrm{O}^{2-}$ ions are formed in the cathode (reaction (R1)) and diffuse though YSZ to the anode under anodic polarization. A monolayer of PtO is formed at the Pt/YSZ (reaction (R3)) while electrochemical oxidation of CO takes place at TPB (reaction (R6)) as (1). Once the TPB and $\mathrm{Pt} / \mathrm{YSZ}$ interface are saturated, the electrochemically formed $\mathrm{PtO}_{x}$ species migrate to the Pt/gas interface as back-spillover promoters inducing the EP effect (2) and simultaneously diffuse through the Pt bulk as oxygen storage (3) leading to pers-EP after polarization as illustrated in Fig. 3.

\section{Conclusion}

A galvanostatic step is applied to Pt/YSZ in the presence of $\mathrm{O}_{2}$ and $\mathrm{CO}$ at $300^{\circ} \mathrm{C}$ and $400^{\circ} \mathrm{C}$ under high vacuum conditions. The catalytic rate presents the electrochemical promotion effect at $300^{\circ} \mathrm{C}$ while only electrochemical oxidation is observed at $400^{\circ} \mathrm{C}$. The measurement of oxygen evolution in the absence of reactive gas is assumed to be a consequence of the instability of electrochemically formed $\mathrm{PtO}_{x}$ species at higher temperature. This means that thermodynamically stable $\mathrm{PtO}_{x}$ over the Pt/gas interface has to be present to induce the electrochemical promotion.

The polarization time has an important influence on the performance of pers-EP while it has no effect on the promoted steady state rate. Such relaxation transient is attributed to the oxygen storage hidden in the non-gas exposed places, i.e. Pt/YSZ interface and Pt 
bulk. Upon current interruption, the stored $O$ species are released to the Pt/gas interface keeping the catalytic rate at the promoted state. In addition, the behavior of pers-EP is affected by the $\mathrm{O}_{2}$ pressure, i.e. longer relaxation time under higher $\mathrm{O}_{2}$ pressure.

\section{Acknowledgement}

This work was supported by the Swiss National Science Foundation.

\section{References}

[1] C.G. Vayenas, S. Bebelis, S. Ladas, Nature 343 (1990) 625-627.

[2] C.G. Vayenas, S. Bebelis, S. Neophytides, J. Phys. Chem. 92 (1988) 5083-5085.

[3] C.G. Vayenas, S. Bebelis, I.V. Yentekakis, H.-G. Lintz, Catal. Today 11 (1992) $303-442$.

[4] C.G. Vayenas, S. Bebelis, C. Pliangos, S. Brosda, D. Tsiplakides, Electrochemical Activation of Catalysis: Promotion, Electrochemical Promotion and Metal-Support Interactions, Kluwer Academic/Plenum Publishers, New York, 2001.

[5] S. Ladas, S. Kennou, S. Bebelis, C.G. Vayenas, J. Phys. Chem. 97 (1993) 8845-8848.

[6] B. Luerßen, J. Janek, S. Günther, M. Kiskinova, R. Imbihl, Phys. Chem. Chem. Phys. 4 (2002) 2673-2679.
[7] M. Makri, C.G. Vayenas, S. Bebelis, K.H. Besocke, C. Cavalca, Surf. Sci. 369 (1996) 351-359.

[8] S.G. Neophytides, D. Tsiplakides, C.G. Vayenas, J. Catal. 178 (1998) 414-428.

[9] R. Imbihl, Prog. Surf. Sci. 85 (2010) 241-278.

[10] C. Falgairette, C. Xia, Y.D. Li, W. Harbich, Ch. Comninellis, J. Appl. Electrochem. 40 (2010) $1893-1900$.

[11] C. Falgairette, C. Xia, Y.D. Li, W. Harbich, G. Foti, Ch. Comninellis, J. Appl. Electrochem. 40 (2010) 1901-1907.

[12] C. Falgairette, Thesis no 4690, EPFL, 2010, http://library.epfl.ch/ theses $/$ ? $\mathrm{nr}=4690$.

[13] C.G.Vayenas, J.N. Michaels, Surf. Sci. 120 (1982) L405-L408.

[14] J. Eaves, Thesis no 2883, EPFL, 2003, http://library.epfl.ch/theses/?nr=2883.

[15] A. Jaccoud, Thesis no 3748, EPFL, 2006, http://library.epfl.ch/theses/?nr=3748.

[16] J. Janek, C. Korte, Solid State Ionics 116 (1999) 181-195.

[17] S. Souentie, C. Xia, C. Falgairette, Y.D. Li, Ch. Comninellis, Electrochem. Commun. $12(2010) 323-326$.

[18] C. Falgairette, G. Foti, Catal. Today 146 (2009) 274-278.

[19] A. Jaccoud, C. Falgairette, G. Foti, Ch. Comninelis, Electrochim. Acta 52 (2007) 7927-7935.

[20] A. Katsaounis, Z. Nikopoulou, X.E. Verykios, C.G. Vayenas, J. Catal. 226 (2004) 197-209.

[21] C. Falgairette, A. Jaccoud, G. Foti, Ch. Comninelis, J. Appl. Electrochem. 38 (2008) 1075-1082.

[22] G. Foti, A. Jaccoud, C. Falgairette, Ch. Comninelis, J. Appl. Electrochem. 23 (2009) 175-179. 